\title{
Value chain analysis and benefit distribution of Pig industry in Vietnam
}

\author{
Qui Hoang Nguyen ${ }^{a}$, Budi Guntoro ${ }^{a^{*}}$, Suci Paramitasari Syahlani ${ }^{a}$ and Nguyen Thuy Linh ${ }^{b}$
}

\begin{abstract}
${ }^{a}$ Department of Livestock Social Economics, Faculty of Animal Science, Universitas Gadjah Mada, Indonesia. Jl. Fauna 3, Bulaksumur, Yogyakarta, 55281, Indonesia

${ }^{b}$ Tra Vinh University, No. 126 Nguyen Thien Thanh Street, Ward 5, Tra Vinh City, Tra Vinh Province, Vietnam

\begin{tabular}{l}
\hline C H R O N I C L E \\
\hline Article history: \\
Received May 5, 2020 \\
Received in revised format June \\
8,2020 \\
Accepted August 122020 \\
Available online \\
August 12 2020 \\
\hline Keywords: \\
Value chain \\
Value added \\
Pig industry \\
Tra Vinh province
\end{tabular}

A B S T R A C T

Livestock sector including pig is developing in Vietnam, which plays a crucial role in the economic structure of Vietnam and meets the demand of Vietnamese. The study was involved 120 pig farmers, 3 retailers, 3 wholesalers, 12 middlemen, 3 slaughterhouses, 12 sellers, 3 processors, and 12 consumers in three districts who were chosen as respondents in the value chain. The study was implemented to determine the value chain and benefit distribution of pig industry in Tra Vinh province. Snowball sampling and purposive method were used in this study. The results show that there were three channels of pig in Tra Vinh province during the context of African Swine Fever (ASF). There were three value chains which were found out in the value chain of pig industry. Middlemen played an important role in the value chain. Both of three passed through slaughterhouse as their slaughtering service. The shortest value chain is from farmer - middlemen-cum-seller - consumer. Farmers contributed a high value-added share in the value chain. It could be concluded that in Tra Vinh province, the longer value chain, the higher price the consumer takes. We suggested that the improvement of the number of pig and stabilization of the value chain of pig industry are the current mission and the strategy to be implemented.
\end{abstract}

(C) 2020 by the authors; license Growing Science, Canada.

\section{Introduction}

Pig industry has been developing in Vietnam which has brought more income for the Vietnamese people and created livelihoods for Vietnamese along the value chain. The consumption of pork is significantly high when compared to other kinds of meats. Pork has accounted for a high percentage of consumed meat in Vietnam reaching $29.7 \mathrm{~kg}$ per capita in 2018 (OECD, 2020). In 2019, African Swine Fever has emerged in Vietnam, more than 2,000,000 million pigs have been culled and a lot of farmers have gone out of business (FAO, 2020). In Vietnam, Vietnamese have chosen pork in the wet market as their behavior. The wet market in Vietnam is the place where there are a lot of activities relating to pork. Figuie and Moustier (2009) recorded that Vietnamese made thirteen trips to food retailers in the market per week, showing the Vietnamese behavior of frequenting traditional fresh markets. Vietnamese bought pork from the wet market and it was the preferred channel for purchasing pork (Lapar \& Tiongco et al., 2011). The value chain is a useful tool that can be used to show how actors in the value chain work together. The relationship between actors in the value chain played an important role in explaining the nature of competitive advantage in pig value chain. There were several studies which recorded significant results. However, there was a lack of information about pig value chain in the South of Vietnam. Pig value chain has been analyzed but mostly in the North of Vietnam. According to Chau et al. (2017), there were four channels of pig flow in the North of Vietnam. The shortest channel was from farmer to slaughter men, to retailer and consumer was the final actor of the value chain. Chau et al. (2017) also recorded that farmers did not have a lot of choices in selling their pigs because of the insufficiency of market information and there was no contract between farmers and buyers. All of pig from

* Corresponding author Tel.: +62 81328854160 Fax.: +62 274521578

E-mail address: budiguntoro@ugm.ac.ir (B. Guntoro)

C 2020 by the authors; licensee Growing Science. doi: $10.5267 /$ j.uscm.2020.8.004 
farmers joined in the supply chain through middlemen or slaughterhouse, thus went to consumers through several intermediaries (Herold et al., 2010). Wen and Phuong (2020) also described that farmers who owned less than 30 swine, sold pig to local traders. Additionally, Man et al. (2020) showed that the value chain of pork in Vietnam encompassed producers, middlemen, slaughtermen, retailers, and consumers and the actors often combine with other activities in the value chain. The pigs were purchased at the farm by middlemen and then slaughtered in the slaughterhouse (Man et al., 2020). Therefore, pork was mostly delivered to the local market. Xuan et al. (2016) described that some private butchers also came to these slaughterhouses to slaughter live pig by using workers there. Chau et al. (2017) debated that the middleman is the first person who contacts farmers then buy swine from them. Slaughterhouse also played a role in the value chain of pigs and in generating the economic value added (Nga et al., 2017). Chau et al. (2017) showed the value added of pigs in the North of Vietnam, 14-25\%. There was a lack of farmer groups or cooperatives in the value chain. It also debated in the study of Scholl et al. (2016), farmer groups in Vietnam focusing on coffee, vegetables, fruits and aquaculture.

In previous studies, the value chain was not only considered in the case of pig but also in other livestock in agriculture system. In case of poultry, Razia et al. (2016) showed that we should stop wet market, up structured slaughterhouse, make policies for pricing control and so on to make efficient market value added. Because chicken products in the value chain passed through the processing in wet market, it cannot be retailed through the supermarket to reach middle- and high-income consumers (Richard and Thomson, 2014). Atsbaha and Lemma (2018) debated that the value chain passed through many actors such as input suppliers, poultry producers, poultry collectors, poultry wholesalers, retailers, restaurants and consumers. In case of cattle, beef processors played important role in beef value chain, the value was from input supplier, farm production, assembly, processing, to distribution and consumer (Joseph et al., 2013). Zekarias et al. (2017) showed that beef value chain was important for income of the farmers, brokers, traders, hotels and restaurants. Input suppliers, producers, collectors, traders, cooperatives, brokers, abattoirs, butchers, processors and consumers were the main actors in the value chain of beef (Ponguru and Kanna, 2015). Baviera-Puig et al. (2017) showed that the value chain of rabbit production passed through many intermediaries such as input suppliers, producers, abattoirs, distribution. Abattoirs took in live animal and left the ready meat for consumption.

In recent years, pig value chain has been changed by a lot of factors which led to the change of activities in the value chain. The value chain of pig industry in Tra Vinh province was not stable. The length of value chain was long in the previous years. Besides, there was no published information about value chain of pig industry in Tra Vinh province. Additionally, in the context of Tra Vinh province, it is important to find out the value chain of pig industry which can be useful information for managing pig trading activities in Tra Vinh province. From these reasons, the study was implemented. The aim of this study was to find out the value chain of pig industry. Thus, analyzing the benefit distribution of actors in the value chain.

\section{Literature and hypothesis development}

The first concept of value chain was from Porter (1985) who defined that a value chain is The basic tool for diagnosing competitive advantage and finding ways to enhance it is the value chain which divides a firm into the discrete activities it performs in designing, producing, marketing, distribution its products or we could understand that it is the sequence of activities which are required to bring a product or service from input to output following conception, through a lot of intermediaries of production phase, delivery to final consumers, and final disposal after use.

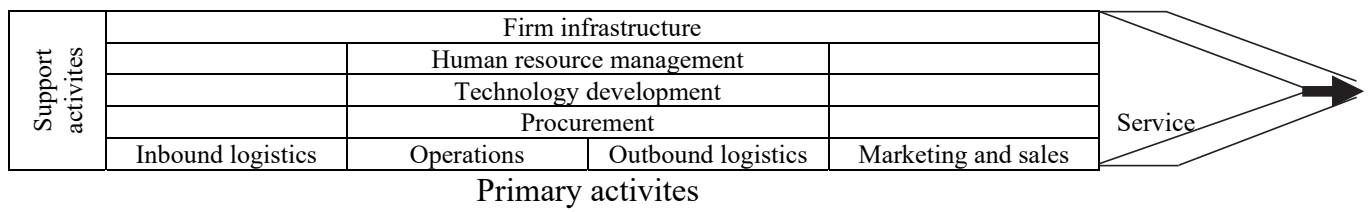

Fig. 1. The generic value chain (Porter, 1985)

According to Porter (1985), there are some primary activities of inbound logistics, operations, outbound logistics, marketing and sales and service which are showed in Figure 1, called value chain model or the genetic of value. It also includes the support activities of the infrastructure of the firm, human resource management, technology development and procurement. In case of developing countries, Rich et al. (2011) recorded that value chain has played an important role in the livestock system. Agri-food networks including livestock provided the livelihood for the rural poor. Rich et al. (2011) also showed that the value chain of agri-food including livestock producers to consumers or purchasing point. Additionally, Trienekens (2011) debated that a network structure of the value chain has two dimensions, called vertical and horizontal. The vertical dimension refers to the flow of products or services from producers to final consumers. The horizontal dimension reflects the relationship between actors in the same value chain or supply chain. Moreover, Herold et al. (2010), Chau et al. (2017) and Wen and Phuong (2020) recorded that the value chain started from the input suppliers to consumers. The study was developed from these researches with the conceptual framework given in Fig. 2. The study was also proved the hypotheses as follow the hypotheses of Herold et al. (2010), Joseph et al. (2013), Ponguru and Kanna (2015), Chau et al. (2017), Zekarias et al. (2017) and Atsbaha and Lemma (2018). 
H1: The value chain has passed through many intermediaries before going to final consumers.

H2: Value added is different between actors in the value chain and middlemen played a crucial role in the value chain H3: The longer value chain, the higher pork price the consumers pay.

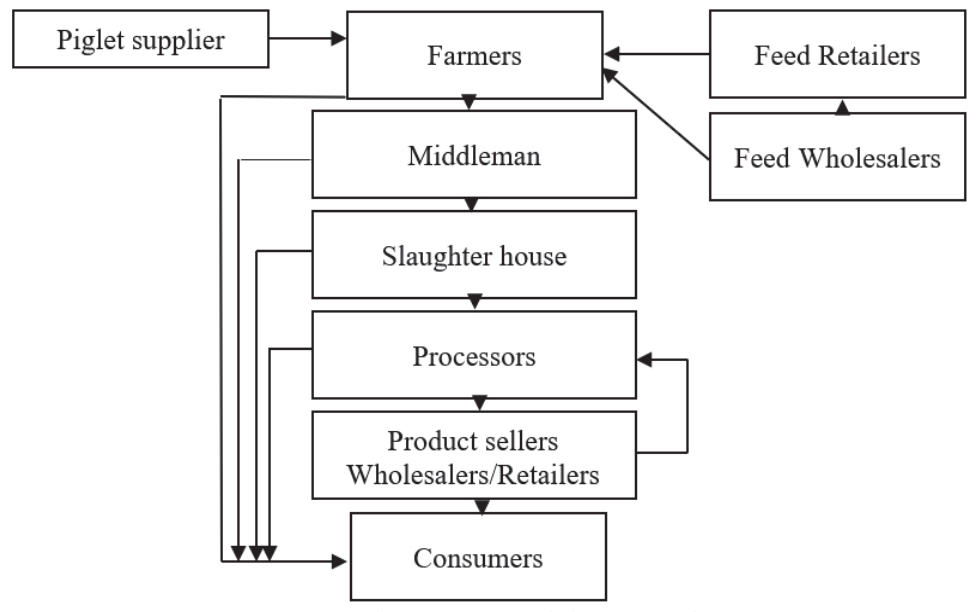

Fig. 2. The conceptual framework

\section{Material and Methods}

\subsection{Location}

Three areas, namely Tieu Can district, Cang Long District and Cau Ke district were chosen as research areas where the population of pig is biggest in 9 districts of Tra Vinh province (GSO, 2019). Besides that, the activities of trading pig in three districts are the busiest which can describe all the performance pig production in Tra Vinh Province.

\subsection{Data collection}

The study was a qualitative research. A total of 162 respondents including 120 farmers, 12 middlemen, 3 slaughterhouses, 3 processors, 12 market sellers and 12 consumers were chosen in three districts as respondents for face-to-face in-depth interview. This study was implemented using snowball sampling method to find out the channels and the actors of value chain. The study was started from the farmers, thus, finding out other actors from information introduced by farmers. Because of unknown population, the purposive sampling method was also used for this research with the criteria:

For the farmers, farmers have at least one-year experience in trading and raising pig

For other actors in the value chain such as feed wholesalers, retailers have experience in selling feed or animal medicine products

For middlemen, slaughterhouse, processors, sellers and consumers have experience in trading or processing pork and pork products

The number of respondents in this study were determined depending on the saturated data from face-to-face in-depth interview or the study continued until there was no new information from face-to-face in-depth interview. Following this method, a total of 162 respondents were generated. For this research, based on the analysis framework, the questionnaires were designed for all entities including of farmers, middleman, slaughterhouse, processors, market sellers and consumers, and the questionnaires were used for face-to-face in-depth personal interview.

\subsection{Data resources}

The type of data used in this study was qualitative data. There was data from the form of numerical figures that can be obtained/gained from questionnaire calculations. There were two sources of data which used to support the study analysis, including: Primary data obtains through the results of face to face in-depth interviews with respondents who were sampled from this study, regrading farmers, animal feed wholesalers, retailers, middleman, slaughterhouse, processors, market sellers and consumers, and also interview according to the prepared questionnaire. Secondary data was an available data which obtains from country reports, state agencies, companies, the information from the research results, articles, magazines of domestic and foreign authors were also systematically consulted. Beside that, secondary data were provided by the Department of Agricultural and Rural Development, and the General Statistics Organization.

\subsection{Data analysis}

The study was calculated the revenue, costs, value added, income of actors in the value chain. The framework following the approach of GTZ (2007) and Hoang (2015) who emphasized the importance of revenue, intermediate cost, added value and profit. Some financial indicators applied in this study can be explained by the formulation as follows: 
Revenue $=$ Output $\times$ Unit price

Margin price $=$ the next revenue - the previous revenue

Total cost $=$ Variable cost + Fixed cost

Net Profit $=$ Revenue - Total cost
Intermediate cost $=$ Cost of raw material + Cost of other inputs, services Added value $=$ Revenue - Intermediate cost

Income $=$ Value added - Total costs

\section{Results}

\subsection{The value chain of pig industry in Tra Vinh province}

There were three value chains which were found out in this study (Fig. 3). Following the Fig. 3, there was a centralized pattern in which pig farmers were independent in selling and trading pigs. The results showed that the first value chain was from farmer - middlemen - slaughterhouse - seller - consumer (Channel 1), the second value chain was from farmer middleman - slaughterhouse - seller - processor - consumer (Channel 2) and the third value chain was from farmer middlemen-cum-seller - slaughterhouse - middlemen-cum-seller - consumer (Channel 3).

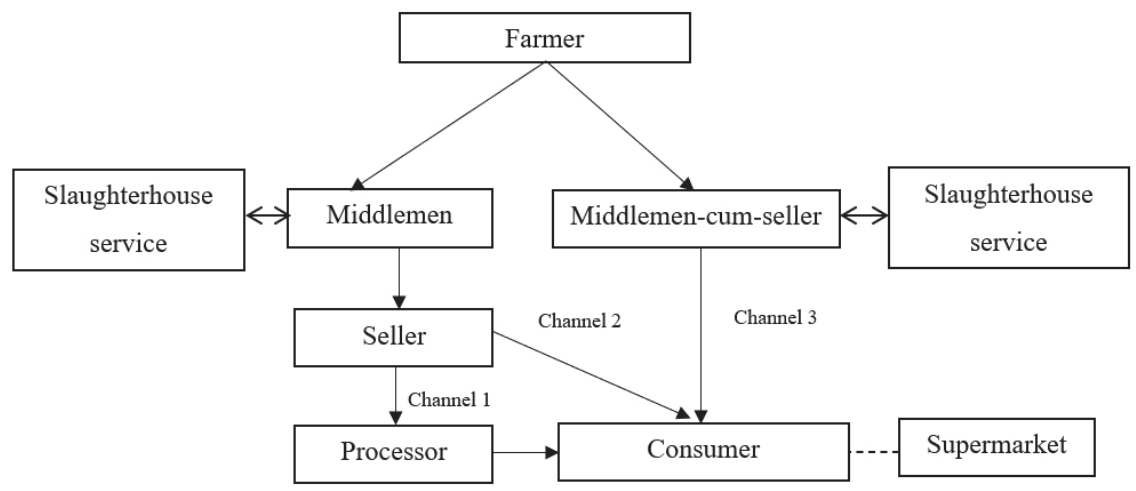

Fig. 3. Mapping the value chain of pig industry in Tra Vinh province

When pig farmers want to sell pigs, middlemen were their choice or we could say that there was only one flow of pigs which was from farmers to middlemen. All farmers in the study confirmed that they sold their pigs to middlemen without other intermediaries. Middlemen were the first choice of farmers to sell live pigs.

"...Actually, I do not want to sell it to other people. It's difficult for me, you know when you want to sell pigs to slaughterhouse for example, you have to prepare transportation, you have to transfer pigs to slaughterhouse and you have to find the consumer after your pigs were slaughter...

...Let's think which way is better? Selling pigs to middleman directly and get money on farm or do a lot of processes and face high risks in selling pork...."

Middlemen buy hog from the farm directly. After that, slaughterhouse service was rent to slaughter pigs. In Tra Vinh province, several middlemen acted as two actors in the value chain or known as middlemen-cum-seller. Middlemen were the people who bought pigs from the farm and they were pork sellers as well. Middlemen came to the farm in the morning and deliver pigs to slaughterhouses after the pigs were weighed.

“...Firstly, I buy pig from farmers. Then, I rent slaughter service. I slaughter pig in slaughterhouse. This is the rule...After buying from farms. I will transfer to the slaughter house and slaughter there. After pigs were slaughtered, I will give for sellers in the market...sometimes, my wife sells pork in the market as well..."

They also said that:

“...I have my own truck. It is easy for me to come to the farm...After reaching an agreement on prices, I will catch with about 5 to 10 swine at a time. I buy swine for the daily demand of the market..."

In Tra Vinh province, slaughterhouses joined in the value chain as a service. They received pigs from middlemen and they gave the service for slaughtering pigs. Slaughterhouse did not buy pig or sell pork in the slaughterhouse.

“...My slaughterhouse just likes a service to help other people slaughter hog. Before, I bought pig, then slaughter, but now I do not do that...Mostly I slaughter for middlemen. Every night, they deliver their pigs to my slaughterhouse and slaughter it. They receive meet around 4 am every day... ... Before, I slaughter for farmers also, but because of ASF epidemic, no farmer comes here to slaughter swine..."

The activities of slaughterhouse always took place at nighttime. Veterinarian was required in the slaughterhouse to check the status of pigs and pork after slaughtering. Middlemen or market sellers got pork from the slaughterhouse by themselves "Every night, a lot of people come here. It is so crowded at night... workers, veterinarian, middlemen, market sellers... Every day, my slaughterhouse operates more than 150 swine. As I know and see every day, pork is collected directly by market seller and middleman themselves..."

Mostly, market sellers in the value chain of Tra Vinh province were retailers. Market sellers can get pork by themselves in the slaughterhouse or through middlemen. 
“...I got pork from middlemen. Because we have contracted to each other. I order pork every day. For example, every day, in the morning, they have to transfer pork to my place. Then, I sell it to the market..."

Other market sellers said:

“...I go to slaughterhouse and get pork directly. However, pork supplier is middleman, not slaughterhouse. I have to wait for pork processing in slaughterhouse, then bring it to the market..."

Processors went to the market and bought pork from market sellers. They did not buy pork from slaughterhouse or other resources. There were diverse products made from pork in processor stage, namely Vietnamese local sausages (namely "Cha", "Lap Xuong", ...).

“...I have friends in the market. My friends sell pork. So, I just order from them. They usually give me good pork which can be used for Lap Xuong ..."

Many processors confirmed that they process sausages for their purpose and for selling to their neighbours.

"...I do not have market target. I just sell for those who want to buy it. Sometimes, I sell it in the market. Sometimes, I sell it at my house. Usually, when consumers have party, they will order it. Then, I make it. The purpose of making sausages is for my family..."

There were two ways that consumers bought pork. Firstly, they bought pork from market sellers. Other way was from supermarket or hypermarket. Many consumer said they did not like frozen pork and frozen pork products.

Consumers mostly bought pork from market sellers. Wet market is available in the morning, some wet markets operate until the evening.

“...Mostly, I buy pork from the market near my home town. I rarely buy pork in supermarket or convenience store... Processed products mostly are bought in the supermarket and convenience store..."

Some consumers have bought pork from supper market. However, the supply chain of pigs of supper market was not from farmers

“...In our supermarket, we have our chain of products, there is no exception of pork. Pork was delivered from supper market chain. It is not from farmers in this area...."

Some consumers said that:

"...we do not like frozen products. Especially frozen pork. I really do not like it, the taste is not good for me..."

One consumer working in clothing factory said:

“...the market is opened from early morning, so I can buy pork whenever I want, even I'm working in industrial area..."

\subsection{Benefit distribution of the value chain}

Table 1

Benefit distribution of the value chain of pig industry in Tra Vinh province

\begin{tabular}{|c|c|c|c|c|c|}
\hline Criteria & Farmer & Middlemen & Seller & Processor & Total \\
\hline \multicolumn{6}{|l|}{ Channel 1} \\
\hline Revenue & 90000 & 134000 & 150000 & - & \multirow{7}{*}{67385} \\
\hline Margin price & - & 5429 & 16000 & - & \\
\hline Intermediate cost & 42105 & 1338 & 134600 & - & \\
\hline Total cost & 526 & 451 & 1000 & - & \\
\hline Value added & 47495 & 4090 & 15400 & - & \\
\hline Net Profit & 89474 & 133549 & 149000 & - & \\
\hline Income & 47368 & 3639 & 14400 & - & \\
\hline \multicolumn{5}{|l|}{ Channel 2} & \multirow{8}{*}{85026} \\
\hline Revenue & 90500 & 9544 & 155000 & 190000 & \\
\hline Margin price & - & 5714 & 20000 & 55000 & \\
\hline Intermediate cost & 40099 & 77 & 135600 & 160000 & \\
\hline Total cost & 446 & 35 & 1500 & 10000 & \\
\hline Value added & 50401 & 327 & 19400 & 30000 & \\
\hline Net Profit & 90054 & 9509 & 153500 & 180000 & \\
\hline Income & 49955 & 2044 & 17900 & 20000 & \\
\hline \multicolumn{5}{|l|}{ Channel 3} & \multirow{8}{*}{195522} \\
\hline Revenue & 90000 & 140000 & 140000 & - & \\
\hline Margin price & - & 11429 & 140000 & - & \\
\hline Intermediate cost & 44216 & 1190 & 500 & - & \\
\hline Total cost & 422 & 392 & 1500 & - & \\
\hline Value added & 45784 & 10238 & 139500 & - & \\
\hline Net Profit & 89578 & 139608 & 138500 & - & \\
\hline Income & 45363 & 9846 & 138000 & - & \\
\hline
\end{tabular}

Along the value chain of pig industry in Tra Vinh province, pig farmers generated about 90,000-90,500 VND per kg which was accounted for a remarkable part of total value added in entire the value chain of swine, from $23 \%$ to $71 \%$. The income of farmers was from $45784 \mathrm{VND}$ to $49955 \mathrm{VND} / \mathrm{kg}$. The price that consumers had to pay for their pork is $140000 \mathrm{VND}$ in the third channel or the shortest channel. Actors in the value chain confirm that they have to pay for the performance of the value chain such as transportation, processing services, tax and so forth.

Farmers confirmed their cost of raising pigs:

“...When we sell pig, we subtract for electric, water, feed, vaccine, medicine fee, veterinary service, then we compute the profit, maybe the profit is around 4.5 million VND per head. But I'm not sure, because it depends on the time, the weight of pig and so forth..."

The cost was confirmed by slaughterhouses: 

slaughtering service to slaughter their pigs. $40.000 \mathrm{VND} /$ head for worker and 7,000 VND/head for veterinarian..."

\section{Discussion}

Farmers sold their pigs to middlemen directly. It was similar to the studies of Chau et al. (2017), Man et al. (2020). They did the process by themselves without rules or regulations from others. They were no cooperatives in the case of Tra Vinh province (Scholl et al., 2016). Generally, it became farmer's behavior. In the case of farmers, middlemen were the first choice of farmers when selling pigs. Farmers rarely owned vehicles by themselves for delivering pigs. Besides, farmers referred to sell pigs to middlemen. Because there was a lack of market information and farmers did not know where they can sell their pigs. Additionally, lack of contract farming and lack of capacity to support the processing and marketing of pigs led farmers to sell pigs to middlemen without contacting other buyers. Moreover, farmers sold their pigs to middlemen because of quick and guaranteed payment for their pigs, the reduction of risks associated with transportation and the reduction of costs associated with the performance of marketing functions. It also recorded in the study of Chau et al. (2017) and Man et al. (2020). Wen and Phuong (2020) also described the same result.

Middlemen in Vietnam are very important. Alderson (1949), Lusch et al. (1993) and Olsson et al. (2013) recorded that middlemen were powerful actors. Middlemen have an important role in the value chain, such as assembly, buying, and transportation. It was recorded in the study of Tram et al. (2017). Middlemen have tried to contact farmers directly to buy pigs at the farm instead of buying pigs from other actors in the value chain. Because middlemen wanted to gain more benefits, they collaborated with other middlemen in the area. Thus, middlemen have more information about pig farms and they can control the price of pigs and give their offering price. It was in line with the study of Chau et al. (2017). Guntoro et al. (2015) also recorded that middlemen had a strong power to determine the price in the value chain. Middleman-cumsellers are common in the value chain of Tra Vinh province because of the high profit they gained. There were two roles that middlemen-cum-seller played in the value chain. They were both middlemen and sellers. Thus, they could almost control the price of whole value chain, especially in the farmer. They might also adjust the price of pigs at the farm and pork in the market to be profitable for them. If the chain was longer, middlemen would lose more benefits. Therefore, middlemen did the process from farm to market. Middlemen owned truck for delivering pigs and pork. Because they wanted to save money from renting transportation and they also wanted to keep pork fresh. It was debated in the study of Bryer et al. (2011). The pigs were slaughtered in the slaughterhouse. Besides, it was the place where contributed jobs for Vietnamese such as slaughter workers and veterinarian. Slaughterhouse did not buy and sell pigs at their slaughterhouse. It was similar in the results of Baviera-Puig et al. (2017), Chau et al. (2017) and Nga et al. (2017). Slaughterhouses in the value chain of pig industry in Tra Vinh province were just a service. It was due to they did not want to face risks of disease transmission. If the disease emerges in their slaughterhouse, they might close their slaughterhouse to prevent transmit disease. It could be explained that in case of ASF, preventing movement of pig is the good way to control loss of benefit. It was also recorded in the study of Lindström et al. (2012), diseases were mostly infected by animal movements and herd contact. Xuan et al. (2016) described that some private butchers also came to slaughterhouses to slaughter live swine by using workers there. The pork was sold by market sellers in the market. Pork was delivered by market sellers themselves or by middlemen. Market sellers were the final node of the distribution channel in some cases. Lam et al. (2013) recorded a similar result. Middleman-cum-seller emerged in the value chain of pigs due to they wanted to control the price of whole market chain from farmers to consumers. It was also the main reason that middleman-cum-seller had a strong effect on the value chain. Pork was delivered to consumers fast or slow depending on pork retailers. Most of pork retailers delivered pork by themselves because they want to save the delivery costs. No seller wanted to store pork in the refrigerators because of the preference of Vietnamese consumers for fresh pork. Wen and Phuong (2020) debated that after processed, pork was delivered to the local market. Xuan et al. (2016) also dated that almost half of sellers delivered pork and carcass by their motorbike.

Pork from market sellers was the choice of processor. Because they did not have any contract to middlemen, slaughterhouses or even farmers. Besides, processors also did not buy pork every day and the amount of pork was not stable so they cannot contract with sellers in the market. For these reasons, processors chose pork from market sellers as their pork resource. the main resource of pork was from wet market which was recorded in the study of Lam et al. (2013). In the value chain, the role of processors was increased gradually because of the urbanization which increased demand in processed and highquality agri-food (Sexton et al. 2013). Kamath et al. (2018) recorded that for pork, the process began in case of high technology processors at the pent, the process finished after all products were packaged. There were different to case of Tra Vinh province because processors here were undertaken small scale processors. Pork was the most common meat which was consumed by Vietnamese. Mostly, Vietnamese consumers bought pork from wet markets or consumers mainly bought pork in retailers in the wet markets. It could be explained that Vietnamese consumer's behaviors in purchasing pork have been affected by Vietnamese culture. Culture defines the custom which people follow to satisfy their needs. As a similar result, Figuie and Moustier (2009) recorded that Vietnamese made thirteen trips to food retailers. It was also in line with the study of Lapar and Tiongco (2011). Besides, the culture has influenced many aspects of people's life, but what people can see clearest is consumer behavior (Duc and Cang, 2018). Additionally, it was in line with the study of Hao et al. (2018). All things such as all sorts of need, living behavior, consumer behavior, and so forth started from the culture. Additionally, 
price, income, career, demand for pork is also affected by the consumer's characteristics. Particularly, age, the gender of buyer, living location and size of household also affect demand for pork (Lam et al., 2013). Other reasons leading consumers to buy pork in the market are the relationship with pork sellers. Pork sellers are neighbors or just the people in the area so consumers believed in their trading. Xuan et al. (2016) also debated that the price and accessibility were less important, consumers emphasized trust in pork sellers and cleanness of seller stalls as factors influenced pork purchasing. Furthermore, consumers can freely access and buy fresh pork at the market at any time. However, there were a few numbers of consumers who chose supermarket or hypermarket as their main resource for purchasing pork. It was due to the evolution of the demand for high quality, safe, and convenient products. It was in line with the studies of Sexton et al. (2013) and Cucagna and Goldsmith (2018). Besides, the development of technologies increased competition, require the production of differentiated products. Thus, modern consumers go to supermarket to fulfill their demand.

The results of value added in this study were higher than the results of Chau et al. (2017) which showed the value added of swine in the North of Vietnam, 14-25\%. It could be explained by the fact that because of the scarcity of pork in Vietnam, each actor in the value chain can create higher value and gain more benefit with the high price of pork. Besides, Vietnamese cannot meet the demand because of the higher price when compared to previous years. Value added generated by other actors in the value chain was different in the same channel and different channels. Because it depended on the location, price, economic status, services and so on. Farmers had the highest income in the value chain. It was different when compared to the study of Chau et al. (2017), farmer is the actor who has the lowest income in the value chain. It was because of the high price of live pig now. Middlemen played an important role in generating value added in the value chain. It was recorded in the study of Olsson et al. (2014), middlemen have to create the value added in some way for its business partners. Between three channels, thee third value chain was the shortest one. Because middlemen play two roles in the value chain, both middlemen and sellers or known as middlemen-cum-seller. Thus, middlemen-cum-seller can generate more benefits in the value chain. It commonly appeared in Tra Vinh province. Antràs and Costinot (2011) also debated that the role of traders and middlemen have been increased in recent years. The shorter the chain, the lower price the consumer takes. It was proved in the result of this study. In the value chain, there were several fees that each actor had to pay for themselves. Therefore, the value added was different between actors in the value chain. Furthermore, there was no way to link farmers and consumers to reduce the intermediary fees in the value chain of pig industry in Tra Vinh province. Producers or farmers allowed their position in the market and do not have bargaining power because they depended on the services of intermediaries. It was also recorded by Guntoro et al. (2015).

\section{Conclusion}

There were three value chains of pig industry which were found out in Tra Vinh province. The shortest value chain included farmers, middlemen-cum-sellers, slaughterhouses and consumers. The value chain of pig industry in Tra Vinh province has passed through many intermediaries before going to final consumers. Farmers had the highest value added in the value chain. Middleman was an important actor in the value chain. Besides, the shorter the value chain, the lower price the consumer paid.

\section{Acknowledgements}

The authors would like to thank the nonymous referees for constructive comments on earlier version of this paper.

\section{References}

Alderson, W. (1949). Scope and place of wholesaling in the United States. The Journal of Marketing, 14, 144-145.

Antràs, P., \& Costinot, A. (2011). Intermediated trade. Quarterly Journal of Economics, 126(3), 1319-1374.

Atsbaha, H., \& Lemma, Z. (2018). Analysis of Current Status of Poultry Value Chain in Ethiopia: Implication for Information Generation and Exchange: A Review. Industrial Engineering Letters, 8(3), 100-111.

Baviera-Puig, A. Buitrago-Vera, J., Escriba-Perez, C., \& Montero-Vicente, L. (2017). Rabbit meat sector value chain. World Rabbit Science, 25(1), 95-108.

Bryer, P.J., Sutherland, M.A., Davis, B.L., Smith, J.F., \& McGlone, J.J. (2011). The effect transport and space allowance on the physiology of breeding age gilts. Livestock Science, 137(1-3), 58-65.

Chau, L.T.M., Lebailly, P., \& Trung, T. Q. (2017). Enhancing farmers' market power and income in the pig value chain; a case study in Bac Giang province, Vietnam. Livestock Research for Rural Development, 29(12), 1-9.

Cucagna, M. E., \& Goldsmith, P. D. (2018). Value adding in the agri-food value chain. International Food and Agribusiness Management Review, 21(1030-2018-1812), 293-316.

Duc, V.M. \& Cang, V.T. (2018). The Impacts of Culture on Vietnamese Consumer Behavior Towards Foreign Products. Social Science, 7(4), 199-202

FAO. (2020). ASF (African swine fever) situation in Asia. Retrieved July 06, 2020 from http://www.fao.org/ag/againfo/programmes/en/empres/ASF/situation update.html

GSO. (2019). General Statistics Organization: Population and Housing $\bar{C}$ ensuses. Ha Noi: Statistics Publishing.

GTZ. (2007). Value Links Manual: The Methodology of Value Chain Promotion. $1^{\text {st }}$ Ed. Deutsche Gesellschaft für Internationale Zusammenarbeit (GIZ). 
Guntoro, B., Rochijan, Widyobroto, B.P., Indratiningsih, Umami, N., Nurtini, S., \& Pertiwiningrum, A. (2015). Constraints of Value Chain in Dairy Industry in Central Java. The $6^{\text {th }}$ International Seminar on Tropical Animal Production: Integrated Approach in Developing Sustainable Tropical Animal Production, 619-623.

Hao, T.N., Quoc, N.C., Amon, K.N. \& Dat, P.T. (2018). Vietnamese Consumers' Willingness to Pay for Safe Pork in Hanoi. Journal of International Food \& Agribusiness Marketing, 31(4), 378-399.

Herold, P., Roessler, R., Willam, A., Momm, H., \& Valle Zárate, A. (2010). Breeding and supply chain systems incorporating local pig breeds for small-scale pig producers in Northwest Vietnam. Livestock Science, 129(1-3), 63-72.

Hoang, V.V. (2015). Value chain analysis and competitiveness assessment of Da xanh Pemelo sector in Ben Tre, Vietnam. Journal of Asian Social Science, 11(2), 8-19.

Joseph, D., Prince, K., \& Hardwick, T. (2013). Value Chain Analysis of Beef in Central and Southern Malawi (Case Studies of Lilongwe and Chikhwawa Districts). International Journal of Business and Social Science, 9(6), 92-102.

Kamath, R. (2018). Food Traceability on Blockchain: Walmart's Pork and Mango Pilots with IBM. The Journal of The British Blockchain Association, 1(1), 47-53.

Lam, D.T., Cuong, T.T., Huyen, N.T.T, Xuan, V.K., \& Duc, N.A. (2013). Analysis of factors affecting demand of pork consumption in Vinh city, Nghe An. Journal of Social and Development, 11(3), 429-438

Lapar, M.L.A., \& Tiongco, M.M. (2011). Private standards in pork value chains: Role, impact and potential for local innovation to improve food safety and enhance smallholder competitiveness. Farm Policy Journal, 8(3), 39-53

Lindström, T., Lewerin, S. S., \& Wennergren, U. (2012). Influence on disease spread dynamics of herd characteristics in a structured livestock industry. Journal of the Royal Society Interface, 9(71), 1287-1294.

Lusch, R., Zizzo, D., \& Kenderdine, J. (1993). Strategic renewal in distribution. Marketing Management, 2(2), 20-29.

Man, N.T.T., Pierre D., Philippe L., Chau L.T.M., Huyen N.T.T \& Veronique, D. (2020). Mapping the pork value chain in Vietnam: a systematic review. Tropical Animal Health and Production, https://doi.org/10.1007/s11250-020-02338-y

Nga, N.T.D., Lapar, M.L., Hung, P.V., Long, T.V., My, P.K., Toan, P.T., \& Unger, F. (2017). An evaluation of economic viability of small-scale slaughterhouses in Vietnam: Implication for pig value chain development. The $9^{\text {th }} A S A E$ International Conference: Transformation in Agricultural and Food Economy in Asia, 813-828.

Nguyen, T.A.T., Bui, C.T.P.N., \& Jolly, C.M. (2017). The Value Chain of Exported White-Leg Shrimp: Case Study in Khanh Hoa Province, Vietnam. International Journal of Food and Agricultural Economics, 5(2), 9-23.

OECD. (2020). Meat consumption (indicator). Retrieved July 06, 2020, from https://doi.org/10.1787/fa290fd0-en

Olsson, R., Gadde, L.-E., \& Hulthén, K. (2013). The changing role of middlemen - Strategic responses to distribution dynamics. Industrial Marketing Management, 42(7), 1131-1140.

Ponguru, C.S.R., \& Kanna, N. V. (2015). Market and Value Chain Analysis of Cattle and Beef in Ethiopia - A Review. International Journal of Social Sciences, Arts and Humanities, 1(2), 51-66.

Porter, M.E. (1985). Competitive Advantage: Creating and Sustaining Superior Performance. New York: NY: Free Press

Razi, K, Shamim A., Hasan, Md. A., Islam, Md. S., Ashab Uddin, A.S.M., \& Mahmud, Md. S. (2016). Value chain analysis of processed poultry products (Egg and Meat) in some selected areas of bangladesh. American Journal of Rural Development, 4(3), 65-70.

Rich, K.M., Ross, R.B., Baker, A.D. \& Negassa, A. (2011). Quantifying value chain analysis in the context of livestock systems in developing countries. Food Policies, 36(2), 214-222.

Richard, B., \& Thomson, K. (2014). An Analysis of the Value Chain for Indigenous Chickens in Zambia 's Lusaka and Central Provinces. Journal of Agricultural Studies, 2(2), 32-51.

Scholl, K., Markemann, A.B., Megersa, R. Birner, A.V., \& Zárate. (2016). Impact of projects initiating group marketing of smallholder farmers-A case study of pig producer marketing groups in Vietnam. Journal of Co-operative Organization and Management, 4(1), 31-41.

Sexton, R.J. (2013). Market Power, Misconceptions, and Modern Agricultural Markets. American Journal of Agricultural Economics, 95, 209-219.

Trienekens, J.H. (2011). Agricultural value chains in developing countries a framework analysis. International Food and Agribusiness Management Review, 14(2), 51-82.

Wen, C.H., \& Phuong, T.V. (2020). Pig Supply Chain Analysis for Improvement and Inclusiveness for Small Scale Producers in Hanoi, Vietnam. FFTC Agricultural Policy Platform.

Xuan S.D, Viet, N.H., Meeyam, T., Fries, R., Nguyen Thanh, H., Pham Duc, P., Steven, L., Delia, G., \& Unger, F. (2016). Food Safety Perceptions and Practices among Smallholder Pork Value Chain Actors in Hung Yen Province, Vietnam. Journal of Food Protection, 79(9), 1490-1497

Zekarias, B., Alemayehu, B., \& Tesfaye, A. (2017). Value Chain Analysis of Beef Cattle Production in Wolaita Zone: The Case of Damot Gale District, Wolaita Sodo, Boditi and Areka Towns, Southern Ethiopia. International Journal of Environmental Sciences \& Natural Resources, 7(1), 19-30.

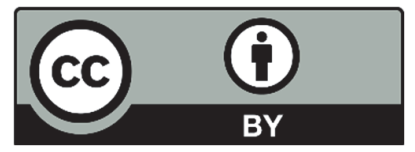

(C) 2020 by the authors; licensee Growing Science, Canada. This is an open access article distributed under the terms and conditions of the Creative Commons Attribution (CC-BY) license (http://creativecommons.org/licenses/by/4.0/). 